\title{
EL DISCURSO OBSESIVO Y LA ADICION COMO ESTRUCTURA EN MULATA DE TAL, DE MIGUEL ANGEL ASTURIAS
}

\author{
POR \\ RAUL SILVA CACERES \\ Universidad de Upsala, Suecia
}

Creo que mi lenguaje en esta novela tiene una nueva dimensión. Está escrita en el lenguaje popular, como una especie de picaresca verbal, con el ingenio y la fantasía que tiene la gente sencilla para hilar frases y jugar con las ideas. Creo que lo primero que debemos observar en Mulata de Tal, más que el argumento o la trama, son sus elementos invisibles, su contenido puramente enigmático ${ }^{1}$.

Estas propias palabras de Miguel Angel Asturias, dichas a Pablo Rojas Guardia a los pocos años de la publicación de la novela que comentamos, encierran una explicación parcial sobre el tipo de discurso narrativo empleado por su autor para contar el asunto. Pero, al mismo tiempo, señalan algunos de los rasgos que pueden servir para caracterizar a toda la primera generación del realismo mágico, sobre todo en lo referente a su rechazo de la linearidad discursiva que llevaba a una simplificación extrema de los contenidos. Los escritores ponían énfasis en hacer resaltar el valor polisémico de la frase literaria, la cual era mirada como una etapa superior de un mecanismo muy complejo presidido por

'Cit. por Pablo Rojas Guardia en La realidad mágica (Caracas: Monte Avila, 1969), pp. 91-92. Estas declaraciones circunscriben las múltiples realizadas con anterioridad tanto sobre su técnica novelesca como sobre su estética narrativa en general. Las más importantes son, sin duda, las hechas a Claude Couffon en Alcor, Asunción del Paragtuay, en 1963: «Mis novelas siguen la tendencia del realismo mágico. Es mágico porque revela un poco el sueño como lo conciben los mayas en sus textos sagrados. Leyendo a estos últimos yo me he dado cuenta de que existe una realidad palpable sobre la que se inserta otra, creada por la imaginación y que se envuelve en tantos detalles que llega a ser tan real como la otra.» (Cf. «M. A. Asturias y el realismo mágico», en la revista mencionada.) 
una fuerte conciencia autorreflexiva, que ellos pretendían negar como praxis de las generaciones anteriores. Simultáneamente había en ellos un interés manifiesto por hacer acceder al nivel de la lectura los elementos ocultos de la realidad, los rasgos profundos y misteriosos que ésta encerraba, junto con una tendencia al ocultamiento y a hacer resaltar «la ambiguiedad» de aquélla. O para decirlo con las propias palabras de Asturias: a revelar sus contenidos enigmáticos más que sus contenidos argumentales. En esta dicotomía, en este constante oscilar entre el «ocultamiento» y la "revelación», se centró gran parte de la crisis histórica y personal del escritor de esa generación, que se enfrentaba a la primera gran crisis de modernidad de América Latina, la cual coincidió con la obvia depresión del mundo capitalista occidental en la década de los treinta. Así, el escritor se dio cuenta de que la novela podía ser un vehículo privilegiado para impulsar el conocimiento del ser cultural y psíquico del latinoamericano, y en el caso de Asturias, se adaptó muy bien a la función que le descubrían las literaturas de vanguardia: un complemento o reemplazo del mito primitivo, articulado en numerosos símbolos y arquetipos propios de la vida moderna. Asturias no renunció a la tradición indígena, sino que la universalizó asimilándola a ciertas técnicas del surrealismo francés: el automatismo verbal, las asociaciones más o menos ilógicas, los juegos de palabras, jitanjáforas, aliteraciones, que le sirvieron para colocar en el mismo nivel la mentalidad indígena animista, sus actos mágicos destinados a conjurar las fuerzas cósmicas, con el relativismo y la «ambigüedad» en que parecía sumida la conciencia histórica del hombre occidental ${ }^{2}$.

Mulata de Tal es una obra tardía en la producción de Asturias, y su publicación en 1963 coincide con el largo camino recorrido por su autor en el exilio, luego de los sucesos que detuvieron el proceso de democratización de Guatemala bajo el gobierno progresista de Jacobo Arbenz. De esta manera, tanto la temática y las modalidades narrativas de trabajos tales como la trilogía bananera o esa obra maestra que es Hombres de maíz, aparecen sólo formalmente retomados por el autor guatemalteco, pero el sentido es diferente. Con Hombres de maíz hay, sin duda, muchas similitudes, incluyendo su punto de partida, pero todo lo que en ésta es equilibrio y desvelamiento de una tradición indígena, todo lo que es asimilación de una tradición nacional a la justicia social y a la historia como fuerza moral de un pueblo, se transforma en Mulata de

2 Véase mi prólogo «Aparición y sentido de la novela actual» al volumen colectivo La novela hispanoamericana actual (New York: Las Américas Publishing Company, 1971; en coedición con Angel Flores). 
Tal en desequilibrio y ocultamiento, en encantamiento verbal teatralizado. Justamente la tendencia a la permanente "escenificación» que ofrece la novela, la cual ha dado origen a un artículo delirante de Gérald Martin comparándola con las películas de dibujos animados y, más concretamente, con Mickey Mouse, Tom y Jerry y Donald Duck ${ }^{3}$, es una de las formas de compensación que se ponen en juego para asumir la insuficiencia de la Historia para explicar los sucesos; pero no nos equivoquemos: la escenificación como principio explicativo del mundo existe en la base del pensamiento indígena, tal como se ve en el Popol Vuh, pero su sentido es diferente. El encuentro con los «salvajes» en la novela (o sea, los hombres-jabalíes), la danza de los gigantones, las intervenciones del sacristán, las nueve vueltas del diablo, son todos episodios de una fantasía caprichosa que va hilando sucesos con una finalidad fundamentalmente lúdica y en donde el equilibrio entre ocultamiento y revelación aparece muchas veces roto.

Dos elementos fundamentales dan origen a la estructura de la novela: una leyenda popular de Guatemala, en la cual se cuenta la historia de un campesino pobre que se hace rico vendiendo su mujer al diablo, lo cual terminará por acarrearle desgracias infinitas, y, en segundo lugar, una variante del mito de la luna y el sol, que existe en las culturas náhuatl y maya-quiché, en el sentido de que ambos no pueden compartir el mismo lecho porque son antagónicos y si lo hicieran engendrarían hijos monstruosos. De este modo, la novela comienza justamente cuando Celestino Yumí, el protagonista, es convencido por el diablo de las hojas del maíz, Tazol, que le venda a su mujer Catalina Zabala, Niniloj, a cambio de monedas de oro que le permitirán superar la riqueza de su compadre Timoteo Teo Timoteo.

Ahora bien, la leyenda popular guatemalteca tiene numerosas variantes, pero Asturias eligió una de ellas, que le convenía para insertar el mito de la luna y el sol, en una muestra de sincretismo muy típico del realismo mágico: eligió la variante en que el diablo huye con la mujer que él ha comprado y luego vuelve disfrazado, a su vez, de mujer a encontrarse con el hombre. Este se enamora del diablo con apariencia femenina y termina por pasarlo muy mal; en efecto, el diablo le hace la vida imposible y el hombre termina por arrepentirse y extraña a su primera mujer, que ahora le parecerá un dechado de virtudes. Siguiendo

3 Véase «The novel as animated cartoon», de Gérald Martin (Hispanic Review, $41,1973)$. Se trata, por otra parte, de un estudio muy bien documentado y con una serie de interesantes sugerencias sobre posibilidades de interpretación a la luz de ciertos textos mayas. 
este esquema, vemos cómo Celestino Yumí encuentra a la Mulata de Tal en la feria pública, se enamora de ella y se casa al poco tiempo. Pero la Mulata revela un carácter frenético e imposible: Yumí no puede tener relaciones normales con ella, porque ésta, un ser lunar, ambiguo, nocturno, no da nunca la cara:

La mulata era terrible. A él, con ser él, cuando estaba de mal humor, se le tiraba a la cara a sacarle los ojos. Y de noche, tendida a su lado, lloraba y le mordía tan duro que no pocas veces su gran boca de fiera soberbia embadurnábase de sangre, sangre que paladeaba y se tragaba, mientras le arañaba, táctil, plural, con los ojos blancos, sin pupilas, los senos llorosos de sudor. Y esto a veces una noche y otra, sin poder dormir, temeroso siempre de que la fiera despertara y lo agarrara desprevenido, explosiones de furor coincidentes con las fases de la luna ${ }^{4}$.

El propio Asturias ha dado algunas claves para la comprensión de este aspecto del libro: ha dicho que la razón de que la Mulata jamás le dé la cara cuando hacen el amor no podría ser explicada claramente, pero afirma que los textos indígenas castigaban severamente a los que hacían el amor vueltos hacia el «lado indebido». A los niveles de significación ya mencionados, Asturias agrega entonces el de los principios morales que regían en la cultura indígena, la cual, en el contacto con el europeo, en su transformación en una cultura «ladina» o mestiza, ha perdido la integridad que antes poseía. En ese sentido, el mundo novelesco, entrevisto como un mundo degradado, en constante descomposición moral, establece justamente la lucha de varios demonios pertenecientes a varias culturas, que se disputan el universo de Quiavicús, la pequeña aldea guatemalteca que servirá de correlato a la ciudad mágica de Tierrapaulita, esa universidad de las brujerías, como el propio Asturias la designa, y en donde tanto Celestino Yumí como su Catalina Zabala terminarán por desaparecer tragados por la destrucción apocalíptica.

Es muy difícil, y esto no ha sido hasta ahora conseguido por la crítica - de ahí la razón de estas notas-, exponer de una manera coherente y exhaustiva el argumento y el desarrollo de los acontecimientos en la novela, porque éstos aparecen hilados de manera caprichosa y abstrusa, y muchas veces se contradicen y enhebran de modo similar al discurso de un loco o de un niño o, simplemente, con la espontaneidad y falta de causalidad con que se cuentan las consejas y leyendas populares, dichas por boca del pueblo.

\footnotetext{
${ }^{4}$ Véase Mulata de tal (Buenos Aires: Editorial Losada, 1974, cuarta edición). Todas las citas de la obra son tomadas de la misma edición.
} 
Ello no impide que el mundo novelesco esté estructurado a la perfección, sobre todo en torno a ciertos núcleos centrales a partir de los cuales la materia narrativa parece expandirse interminablemente. E1 hecho principal, junto con la lunaridad astral de la Mulata, es que el campesino Yumí es víctima del engaño de un demonio subalterno que no representa las esencias del pueblo indígena de Guatemala, pueblo de los hijos del maíz, pueblo de la sustancia del maíz, sino de un diablo, Tazol, hecho de las hojas del maíz, o sea, de los desperdicios de ese alimento básico de la comunidad indígena del subcontinente. Al respecto, recordemos que en el habla popular de Guatemala se llama «tazol» a las hojas del maíz, al desperdicio de la mazorca. A la inversa, Celestino Yumí representa, a pesar de sus actos condenables y veniales, la mazorca misma, está hecho de la sustancia sagrada, según el Popol Vuh ${ }^{5}$. Por eso es que tiene «el esqueleto de oro» y eso es lo que despierta la codicia de la Mulata:

... y allí mismo el aullido (de la Mulata), el más angustioso aullido al encontrarse de nuevo con su yo lunar, vertebral, horadado, pasivo, climatérico, y allí mismo al replegarse con tristeza de simio que se afila las uñas en los dientes al oír la noticia, la terrible noticia: Yumí, su marido, tenía el esqueleto de oro. Le cortaría un brazo, después el otro, después una pierna, después la otra, y lo metería en una troj, tórax y cabeza de oro blanco, en espera de su muerte, para descarnarlo, botar lo putrescible y extraer intacto el resto del tesoro...6

Pero hay una gran distancia entre nuestro protagonista y Gaspar Ilón, el protagonista de Hombres de maíz: aquél asume la función de héroe

${ }^{5}$ El saber indígena es un saber encuadrante, matemático, que se presenta como una conquista semimágica sobre las fuerzas caóticas de la naturaleza. En el Popol Vuh la creación del hombre de maíz, nacido de la unión del Maestro Mago con la Mujer de la Sangre, hija de uno de los poderosos señores de Xibalbá, tiene ese mismo signo. El hombre de barro, Zibak, representa una etapa anterior en este desarrollo. Es interesante recordar cómo Asturias recogió, aunque dándole un sentido algo diferente, la proliferación de animales y bichos que se mencionan en este texto sagrado: el piojo, las hormigas, los segadores de tallos, el puercoespín, el conejo, etc.

Digamos de paso también que Tazol, el diablo de las hojas de maíz, tiene reminiscencias del dios Tlazoltéotl, que en la cosmogonía náhuatl está dotado de una ambigüedad esencial hombre-mujer y es símbolo de la fertilidad de la tierra y también de las potencias de la noche. En este como en otros casos Asturias hace un uso extenso y variado de la tradición indígena mesoamericana, mezclando, fundiendo, adaptando sus elementos para producir ese sincretismo, que es rasgo fundamental de su generación.

'Mulata de Tal, op. cit., p. 49. 
mítico en la conciencia de su pueblo, precisamente porque es quien encabeza la resistencia de los hombres de maíz contra los maiceros o explotadores encabezados por el coronel Chalo Godoy. Yumí sólo lucha por su enriquecimiento personal, y sus aventuras desmesuradas en la novela que estudiamos son la consecuencia de las desgracias que recaen sobre él y sobre la comunidad indígena de Quiavicús, por su conducta deleznable.

En un sentido más amplio puede afirmarse que Mulata de Tal es una obra en la cual se recogen las tensiones del conflicto cultural que opone a la Guatemala indígena de ese otro país colonizado por los españoles y que terminó por destruir la pureza de una herencia cultural aborigen, una rica cultura con sus tradiciones, leyendas, lengua y religión, para crear una realidad mestiza, la cual es vista por Asturias como espúrea, utilitaria, degradada. E1 personaje de la Mulata encarna todas esas alternativas con sus dimensiones demoníacas, su mestizaje racial y espiritual, su violencia y codicia y, más aún, su ambiguiedad lunar.

Así, el conflicto en la novela adquiere desde el comienzo dimensiones telúricas y cósmicas y depasa largamente el conflicto individual, el cual asume aspectos a ratos irrisorios, cómicos o grotescos con los dos protagonistas que cambian permanentemente de identidad y dimensiones físicas.

La pugna principal está encarnada por la lucha constante entre los demonios indios, mestizos y cristianos que se disputan el mundo de Quiavicús y en el fondo del alma de los dos campesinos. El primero de ellos es el ya mencionado Tazol, diablo de las hojas del maíz, quien preside el mundo de Quiavicús y más concretamente compra a la campesina Catalina pagándola con oro y riquezas materiales.

En él y el segundo de los demonios, llamado Cashtoc, el Grande, demonio telúrico o de la tierra colorada, se establece una relación de dependencia y jerarquía: en efecto, Tazol rinde homenaje al gran Cashtoc, el cual preside las luchas en la ciudad de Tierrapaulita, ese correlato mágico de Quiavicús, luchas que llevan el signo de lo cristiano y lo pagano al mismo tiempo. El tercer gran demonio de la obra es Candanga, un demonio cristiano y ladino, es decir, mestizo, cuya lucha a muerte con Cashtoc cogerá a Celestino y Catalina en una vorágine sin fin hasta la destrucción del mundo de Tierrapaulita. La estructura de acontecimiento progresivo y el sistema de adición continuo de la novela están, sin embargo, enmarcados por un espacio poético-cultural perfectamente claro. Para ejemplo, permítasenos exponerlo gráficamente: 


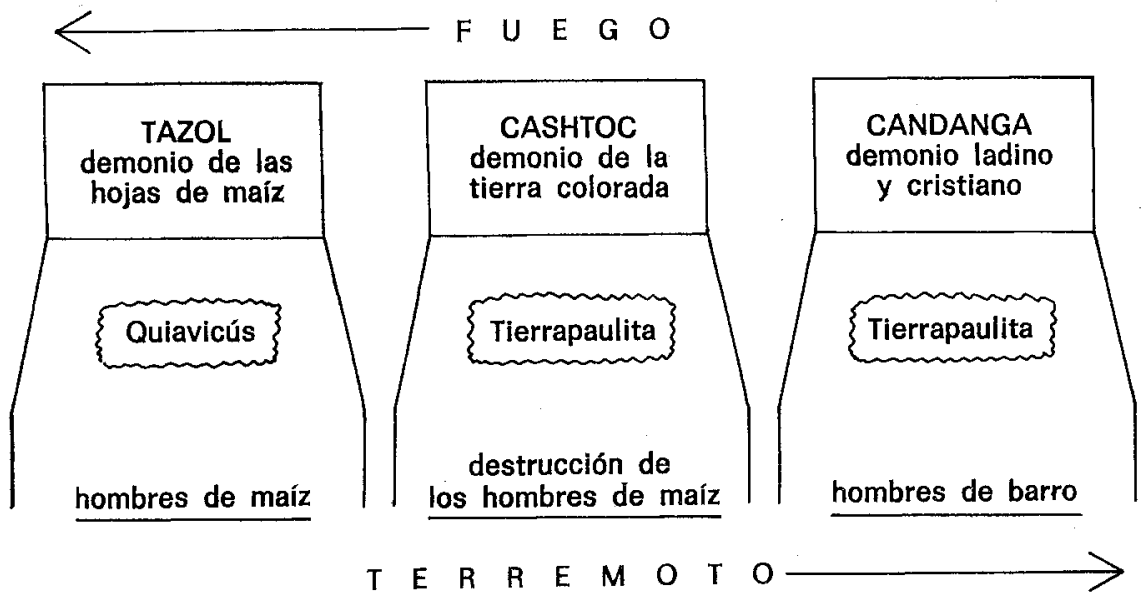

Cada uno de los tres grandes demonios preside un sector del mundo novelesco, el cual está enmarcado por la destrucción: en el primer caso, el de Quiavicús, por el fuego, que es purificación al mismo tiempo que castigo, tal como se estipula en el Popol Vuh o en el Memorial de Sololá de los Cakchiquels. Y en el segundo, por los grandes terremotos que asolan a Tierrapaulita. Pero sería exagerado pretender que esta sistematización es exclusiva y excluyente. En verdad, la novela tiene una estructura de avance vertiginoso que hace muy difícil percibir el espacio como algo hierático y organizado. De hecho, uno y otro sector del gráfico número 1 se interpenetran y modifican constantemente y los demonios pasan y actúan de un lado al otro con frecuencia.

Esta andadura de avance se hace posible por el sistema de la adición de escenas a la manera de cuadros de representación, que dan al lector la sensación de asistir a un teatro de muñecos o de títeres y en donde los personajes cambian de identidad y de tamaño de manera vertiginosa. Ahora bien, el hecho de que tanto Catalina como Celestino lo hagan con frecuencia tiene, por cierto, una significación profunda que va más allá de lo lúdico o lo feérico. Como consecuencia de las desgracias que se abaten sobre él, Yumí es leñatero, rico propietario, pobre otra vez, enano, gigante, indio; su nombre varía también y es llamado Jayumijajá, Chiltic, y puede compartir otras identidades como José Quiquín, Blas Pirir, Genitivo Rancún, Evaristo Tupuc, etc. Por su parte, Catalina es transformada en enana y luego recupera su tamaño y es dotada con el mismo poder para cambiar el tamaño de las gentes; sus nombres también varían, y es llamada de la misma manera Jazabalajajá y luego Giroma. 
Nos parece importante señalar que estas metamorfosis operan en dos niveles: el cambio de nombre y apariencia física por un lado y el aumento y disminución de tamaño por el otro. Ellas son típicas de la literatura fantástica y de los cuentos de hadas infantiles.

Ellas se dan, como es tradicional en el género, como un castigo o recompensa por acciones realizadas con anterioridad, cuando la transformación adquiere rasgos definitivos y permanentes. Cuando ella es transitoria, entonces sucede en los cuentos de hadas o infantiles que adquiere la categoría de una prueba que hay que pasar para obtener el éxito final. Nada de esto último acontece en Mulata de Tal. Las transformaciones de nombre, aspecto y tamaño son producto de la destrucción del mundo personal y posiblemente de la inestabilidad del mundo histórico del indio de Quiavicús y son más cercanas de la visión de un Jonathan Swift o un Lewis Carroll que del mundo mágico de Cenicienta. Pero hay más. Asturias es también capaz de asumir la tradición cultural del indígena e insertarla y acercarla a una óptica universal, y de ahí su grandeza. Los cambios de identidad de Catalina y Celestino están también referidos a la existencia de «nahuales», o sea, de «dobles» en que se cree que se deposita parte de la vida de un hombre, para que tanto éste como aquél (es generalmente un animal) sigan la misma suerte. La existencia de "nahuales» es un hecho corrientemente aceptado en Guatemala, y gran parte del desarrollo novelesco de Hombres de maíz tenía que ver con el tema. La palabra proviene del término «nahualli», que significa «el animal» en lengua azteca. Es un derivado del verbo «nahuá», que significa andar asido de la mano, andar junto con alguien. Por medio del «nahual» o «doble» de una persona se le puede causar sufrimientos y aun la muerte, introducir cuerpos extraños, piedras, gusanos, con el fin de producir daño, o simplemente curar a un enfermo o, en no pocos casos, modificar su conducta ${ }^{7}$.

La mentalidad indígena es muy cercana de la mentalidad mítica, según lo entiende Asturias, y recurre a la magia como arma efectiva para dominar las potencias externas, recurre con naturalidad a lo fantástico como modo de apropiación del mundo. Para decirlo en el mismo sentido

${ }^{7}$ En ciertas zonas de Mesoamérica la connotación es francamente negativa y se refiere como a un indio viejo y feo que se transformará de noche en animal para salir a robar y espantar a las gentes. Según mencionan los textos antiguos, Sahagún, por ejemplo, el origen probable es el de indios «persistentes en su antigua idolatría» que se escondían de las autoridades cristianas para ejecutar sus ritos secretamente. Por extensión se usa como sinónimo de brujo. (Cit. por Birgitta Leander en Herencia cultural del mundo náhuatl, México: Sep Setentas, 1972, segunda edición.) 
de Ernest Cassirer, es el modo en que los fenómenos naturales o cósmicos pasan a depender de los hechos humanos y hacen que los hombres no se sientan a merced de las fuerzas externas a ellos. Por eso es que en Mulata de Tal las fronteras aparecen abolidas y los acontecimientos vertiginosos y fantásticos se viven con toda naturalidad: el mundo está estructurado a partir de una mentalidad ilógica que se expresa a través de dos formas peculiares: el discurso obsesivo y la transposición ${ }^{8}$.

Entendemos por el primero una narración fuertemente proyectada por la tercera persona del singular, que se repite, se busca a sí misma, trata de afirmarse, busca correspondencias a partir de analogías, sonoridad de las palabras, asociaciones mentales y que se parece mucho al discurso de un paciente que habla a veces con incoherencias y trata de recordar sucesos, luego de un cataclismo mayor. Por su parte, la transposición agrega a los rasgos anteriores el del desdoblamiento de escenas y de objetos y obedece en un grado aún más agudo a la ruptura entre el ser (el narrador histórico y/o real) y el mundo. Aparte de la ya mencionada alteración de tamaño y nombre de los personajes principales, se podría agregar en este rubro el de la encarnación «aberrante», como sería el caso de Cashtoc, el diablo pagano, quien se encarna en el sacristán Jerónimo de la Degollación, y la de Candanga, diablo cristiano, en Celestino Yumí, indígena con el esqueleto de oro.

Tanto el discurso obsesivo como la transposición tienen la particularidad de ocultar o desviar ciertos hechos básicos, o bien de iluminar otros de un modo diferente a lo esperado, constituyendo un elemento importante en ese juego de «ocultamiento» y «revelación» a que aludíamos al principio y que nos parecía estar ligado a la supuesta «ambigüedad» de la realidad histórica. Así, al final de la obra vemos cómo Yumí, en el monólogo «Está temblando en la luna», había muerto en el terremoto de Tierrapaulita con su cabeza aplastada y tenía un esqueleto de huesos blancos y normales, y no de oro, como quería la tradición, cosa que temía y deseaba, simultáneamente, la Mulata. Permítasenos, a la luz de lo dicho, completar el cuadro anterior con los rasgos que definen a los personajes y al tipo de narración:

\footnotetext{
${ }^{8}$ Somos conscientes de las connotaciones psiquiátricas que conllevan ambos términos. Pero es evidente que hay una relación entre la proliferación vertiginosa de sucesos, la incoherencia y la fragmentación en la novela, y la proyección de un narrador escindido que recoge la visión de la oposición irreconciliable de contrarios: la mulata como símbolo de la cosmogonía lunar y Celestino del mundo solar. Cuando nos referimos al discurso obsesivo no pensamos en el monólogo interior, algo muy diverso, nacido de la inmediatez e interiorización de la corriente de la conciencia, expresado siempre en la primera persona del singular, sino en una narración menos enmarcada que se expresa en la tercera persona.
} 


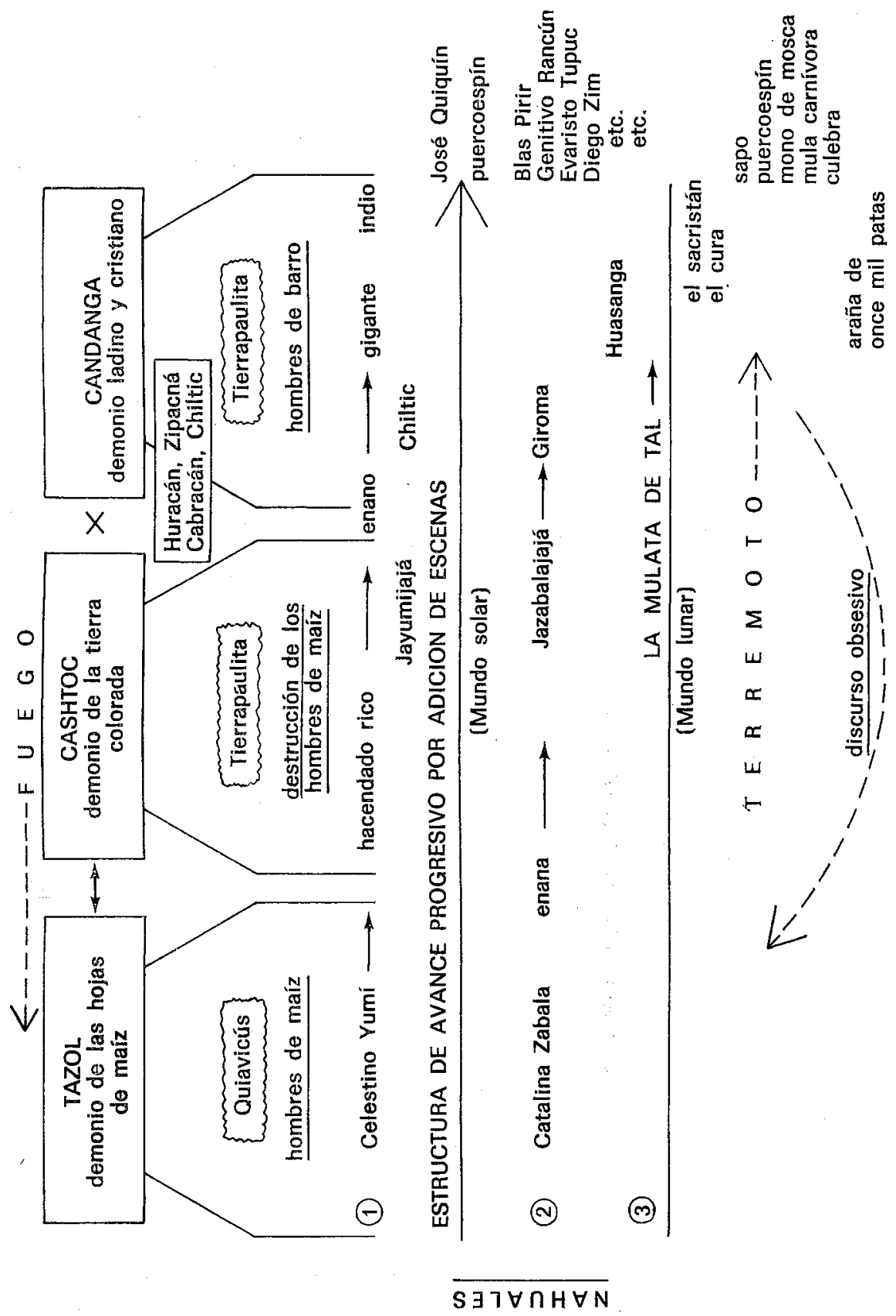


Si nos hemos abocado a transcribir este cuadro es sólo con una finalidad didáctica que permita poner un cierto orden en la comprensión de las tensiones internas que dan origen a la compleja estructura de Mulata de Tal. La masa de sucesos, la obsesión demoníaca con que son contados, el deseo de su autor de que sean percibidos por su «contenido enigmático», hace difícil encontrar centros en la novela que permitan una explicación cartesiana de su contenido. Sin embargo, estos centros existen, aunque sumergidos en la voz enronquecida y confusa de los demonios de Tierrapaulita. He aquí el que nos parece capital:

Una polvareda fue la creación y una polvareda queda de las ciudades que destruimos. ¡No más ciudades! ¡No más hombres que no son sino apariencia de seres, como el formado de barro, que se deshizo solo, y el de madera, colgado como simio, de los árboles! Los hombres verdaderos, los hechos de maíz, dejan de existir realmente y se vuelven seres ficticios, cuando no viven para la comunidad y por eso deben ser suprimidos. Por eso aniquilé con mis Gigantes mayores, y aniquilaré mientras no se enmienden, a todos aquellos que olvidando, contradiciendo a negando su condición de granos de maíz, partes de una mazorca, se tornan egocentristas, egoístas, individualistas... ${ }^{9}$

Es cierto, como ha afirmado ya la crítica, que Mulata de Tal significa un retorno al mundo de las Leyendas de Guatemala. Pero a diferencia de aquéllas, cuya legitimidad nacía de la asunción de una tradición viva en la memoria colectiva del pueblo guatemalteco, esta gran novela tardía de Asturias se pierde en el dédalo de la abstracción y de lo lúdico y rechaza lo poético-novelesco como un elemento integrador de la Historia, tal como fue el caso de la trilogía bananera u Hombres de maíz o de $E l$ señor presidente. Dos hechos importantes, sin embargo, quedan en pie en cuanto a la intención del escritor de Guatemala: el deseo de reflejar a través de la narración una nueva realidad poética, el mundo interior del indio, el cual es muy diverso de los criterios racionales con que lo mide el hombre occidental, y, en seguida, el hecho de que Asturias, a pesar de todo, no es indio y ni siquiera habla la lengua indígena de su patria (como fue el caso de José María Arguedas, por ejemplo), pero siente, desde su mestizaje racial y cultural, la necesidad de interpretar a ese indio. Labor que posiblemente aparecía como muy difícil después de los largos años de ausencia de su tierra natal. Tal vez por eso no estuvo en condiciones de elegir un camino, una elaboración técnica que le permitiera una conceptualización histórica junto con la articulación de una poética, como fue el caso excelso de Hombres de maíz. El camino

\footnotetext{
${ }^{9}$ Asturias, Mulata de Tal, op. cit., p. 172.
} 
elegido es, pues, el de la interioridad y el subjetivismo extremos, un camino en que la óptica «iluminante» del realismo mágico se transforma en una distorsión casi gótica de abultamiento e incoherencia. Así, Asturias elige una estructura y una modalidad movedizas, en la cual el ocultamiento termina por imponerse largamente gracias a este deambular irrestricto entre el sueño y la vigilia, la magia y la representación, el teatro de títeres y el "gran guiñol». El último personaje vivo al final del cataclismo de Tierrapaulita hace justamente retornar toda la masa de sucesos a su lugar de origen, negándose a sí mismo, negando la Historia, podría afirmarse, al disolver todo lo dicho y vivido en «las catedrales de los tímpanos», como si de esa gran sinfonía policroma y afiebrada no quedara sino un hilito que terminará por recogerse y desaparecer en el vago silencio de la memoria.

París-Estocolmo, 1979. 